\title{
Evaluación de la política de privatización en las empresas estatales de Colombia. Análisis del caso Telecom (1990-2010)
}

\author{
Evaluation of privatization policy in the State company of Colombia: \\ Analysis of cases Telecom 1990-2010
}

Recibido: 02-03-2019 • Aprobado: 28-05-2019 • Página inicial: 63 - Página final: 86

\author{
Jairo Bautista* \\ Didier A. Sepúlveda Reyes**
}

\begin{abstract}
Resumen: es indiscutible el efecto de las privatizaciones en el sector público, tanto en las finanzas del Estado como en la prestación de los servicios. Si bien, las privatizaciones surgen como un medio para que los servicios sean eficientes y con alto grado de efectividad para el receptor de los mismos, en Colombia no se ha dado un escenario de evaluación de los resultados de la política de privatización en términos de impacto sobre el bienestar social o la eficiencia económica, sino, que se han sustentado en detalles fiscales, limitado a revisiones de los ingresos del Estado a corto plazo. Esta investigación emprende un análisis del caso de Telecom, que supere la estrecha visión del beneficio financiero y se perciban los efectos sociales de la política de privatización. Además, se plantea una propuesta metodológica para la evaluación de los impactos sobre el bienestar de los usuarios, en términos de beneficios del sistema de tarifas, mejoramiento en la calidad del servicio, y la eficiencia económica.
\end{abstract}

Palabras clave: privatización, globalización, eficiencia, telecomunicaciones, Telecom.

\begin{abstract}
Abtract: The effect of privatizations is indisputable in the public sector, both in the finances of the state and in the presentation of services. While, the privatization arises as a means for services to be effective and with high degree of effectiveness, for the receiver of them. In Colombia you has not been in a scenario for evaluating the results of the privatization policy, in terms of impact on social welfare or economic efficiency, rather, they have been based of fiscal details, limited to revisions of the State's income in the short term. This research undertake an analysis of cases of Telecom, which overcomes the narrow vision of the financial benefit and the social effects of the privatization policy are perceived. Also, It poses a methodological proposal for the evaluation of impacts on the welfare of users, In terms of benefits of the tariff system, improvement in service quality, and economic efficiency.
\end{abstract}

Keywords: Privatization, globalization, efficiency telecommunications, TELECOM.

JEL: H40 - H41 - H42

* Contador Público y Magíster en Administración Pública. Docente - Investigador de la Universidad Santo Tomás, Colombia. Miembro del grupo de Investigación Contaduría: información, control e impacto social de la misma universidad. abautistaj@unal.edu.co

ORCID: https://orcid.org/0000-0003-1344-1692

** Administrador Público y Magíster en Planeación para el Desarrollo. Investigador del Grupo Ciudadanía y Finanzas Públicas, adscrito a la Escuela Superior de Administración Pública - ESAP, Colombia.

didier.sepulveda155@esap.gov.co

ORCID: https://orcid.org/0000-0002-9766-2662 


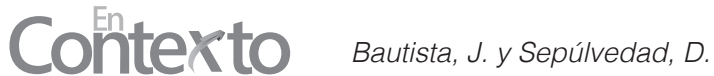

\section{Avaliação da política de privatização nas empresas estatais da Colômbia. Análise de caso TELECOM 1990-2010}

Resumo: o efeito da privatização do sector público, tanto nas finanças do Estado e sua prestação de serviços é indiscutível. Embora, a privatização surge como um meio para tornar os serviços eficientes e com um alto grau de eficácia para o receptor do mesmo, na Colômbia uma fase de avaliação dos resultados da política de privatização não foi em termos de impacto no bem-estar social ou eficácia económica, mas que foram apoiados pelos detalhes de imposto, limitadas a revisões para os rendimentos do Estado, a curto prazo. Esta pesquisa compromete-se a uma análise do caso de Telecom, que ultrapassa a visão estreita do benefício financeiro e recebeu os efeitos sociais da política de privatização. Ele também gera uma proposta metodológica para a avaliação dos impactos sobre o bem-estar dos usuários, em termos dos benefícios do sistema de taxas, melhoria da qualidade do serviço e eficiência econômica.

Palavras-chave: privatização, globalização, eficiência, telecomunicações. 


\section{Introducción}

El término globalización puede ser visualizado como el proceso por el cual se generan los cambios en la estructura de la producción del capitalismo industrial y financiero nacional al capitalismo mundial, aquí surge la empresa nacional; este proceso crea una competitividad mundial que tiene costos muy altos, sobre todo en países no-industrializados.

La privatización, bajo el contexto de la globalización y la presión de las economías hacia el mercado mundial, se considera uno de los principales instrumentos de ejecución del modelo neoliberal, entre cuyos presupuestos figura, en primer lugar, la reducción del tamaño y las funciones del Estado y el fortalecimiento de la economía de mercado. Sus propugnadores no vacilan en presentar la privatización como una estrategia importante de desarrollo, y como una opción que puede conducir a un mejor aprovechamiento de los recursos, con miras a alcanzar un crecimiento más rápido y un mayor bienestar (Matías, 2001, p.25).

El análisis de las políticas públicas se ha venido convirtiendo en un campo de investigación y conocimiento de gran importancia en la actualidad, relacionado con el qué y el cómo hacer del Estado (Matías, 2001, p.25). Particularmente importantes son las reformas del Estado presionadas por las políticas de ajuste fiscal del Fondo Monetario Internacional, de reducción del Estado a su mínima expresión y del predominio del mercado, de las privatizaciones y de la "internacionalización" de la economía. El enfoque del presente artículo es la discusión frente a la política de privatización en Colombia, los avances en términos jurídicos vistos en el caso de la exempresa estatal Telecom, que visibiliza los procesos de desmonopolización y desregulación en uno de los sectores más rentísticos del Estado, como es el de las telecomunicaciones.

A continuación se esboza un marco conceptual que referencia el contexto del fenómeno de la privatización, las discusiones sobre la definición de la privatización y una propuesta conceptual y analítica propia, seguidamente se hacen algunas precisiones discursivas y legales sobre la política de privatización en Colombia y, finalmente, el estudio de esta política en el proceso de privatización de Telecom, analizado en dos momentos cruciales: 1990-2003 y 2003-2006. Finalmente, se plantea una propuesta metodológica para la evaluación de las privatizaciones, específicamente para medir el impacto social. 


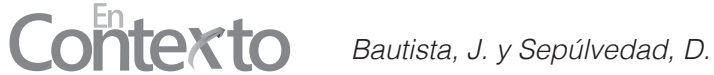

\section{Marco conceptual del fenómeno privatizador}

Las discusiones en torno a la propiedad pública o privada y los esquemas de la toma de decisiones en las organizaciones, son temas que si bien es cierto se han reconocido como un asunto de negocios, y si se quiere de la gestión pública y privada, han permitido identificar transformaciones fundamentales en la concepción del patrimonio público, el bienestar social y la confianza.

El inicio de los procesos de privatización de las empresas públicas puede encontrarse, históricamente, en el programa de privatización lanzado por Margaret Thatcher en el año 1979. Posteriormente, durante finales de los ochenta y especialmente durante los noventa, se llevaron a cabo procesos de privatización en otros países europeos, como Francia, Italia y España. En muchos países los procesos de privatización han formado parte de políticas más amplias de estabilización, desregulación y reforma estructural (Cabeza, 2011, p.45).

La política neoliberal implementada en Latinoamérica, así como los procesos de reestructuración industrial o apertura económica han sido promovidos desde 1980 por el Banco Mundial y el Fondo Monetario Internacional. Estas agencias financieras sobre la base de que el modelo de desarrollo hacia adentro, basado en el proteccionismo y la intervención estatal, imperantes entre países como Colombia por décadas, había entrado en bancarrota, en su reemplazo el modelo de desarrollo hacia afuera inspirado en la drástica reducción de la injerencia estatal, la eliminación del proteccionismo y la erección del libre mercado, es perfilado como la fuente y la razón del progreso actualmente (Matías, 2001, p.26).

La agenda privatizadora, sin ser una innovación en los mercados, se constituyó para el caso latinoamericano, con el Consenso de Washington II, en un elemento de reflexión y decisión en las políticas públicas. La privatización en aquel documento fue concebida como un mecanismo para eliminar firmas estatales ineficientes e insolventes, con el fin de avanzar en la consolidación de economías competitivas, esto hizo posible un escenario en el que los modelos de venta y concesiones de activos, desregulación y nuevas formas de contratación, gestión y financiamiento de la operación de las instituciones estatales son la posibilidad para el cambio. Así, la privatización ha sido sinónimo de reducción del intervencionismo estatal, la enajenación de parte o de toda la propiedad de las empresas estatales y, en general, de nuevas formas supuestamente más eficientes de la gestión y la producción de bienes y servicios.

De esta manera, el fenómeno de las privatizaciones parte de la justificación que otorga el fracaso de la empresa pública en términos de eficiencia económica, 
incentivos, cargas presupuestales y corrupción política. El replanteamiento de la relación ciudadano - Estado y con ello de sus empresas, y de estas con la institucionalidad pública en general, pusieron sobre la mesa como propuestas la descentralización y la privatización.

Otras posturas exponen que en la década de los noventa, partiendo de los cuestionamientos formulados alrededor de las reformas de primera y segunda generación, las tendencias de gestión en lo público se alinean a la perspectiva de la nueva administración pública, que incorpora métodos de la gestión de la empresa como mecanismo para hacer frente a la denominada ineficiencia de las instituciones estatales y/o públicas que restan dinamismo al desarrollo económico.

En 2002 el Banco Mundial, en su informe sobre el desarrollo mundial, indicaba que algunos ejes de análisis en torno a las instituciones y los mercados estaban relacionados con la innovación, como la forma para lograr instituciones eficaces; la competencia, que conduce al cambio institucional y que en general repercute en la rentabilidad relativa y modifica los incentivos de los agentes, y la complementariedad, que plantea la necesidad de avanzar en la abolición de talanqueras a la competencia y a la necesidad de ver, en la escena globalizada, nuevas formas sostenibles de operación del capital, más o menos concentradas, pero altamente competitivas.

\section{La privatización: un concepto en construcción}

Privatizar propone una alternativa novedosa en el manejo de los negocios del Estado, sin embargo, las políticas de privatización no han sido igualmente aceptadas en todos los países. La aceptación o no de la privatización como mecanismo de "modernización" de la administración pública depende del marco institucional de cada país (interés del gobierno, resistencias políticas, etc.), no obstante, lo que se puede verificar en todos los países de América Latina es una tendencia de los Estados a reducir su marco de intervención, siendo la privatización entonces un retorno a las justas proporciones de la intervención estatal, intervención cuyos límites deben pertenecer a la esfera de los "mínimos posibles" tal como señalaran Von Mises y Hayek (Hayek, 2002, p.58).

Ahora bien, cuando se habla de privatización, usualmente se hace alusión a la venta de un activo público o estatal a un agente privado (Cárdenas, 1994). Esta simple definición requiere que se tenga un marco con una serie clara de actores: 


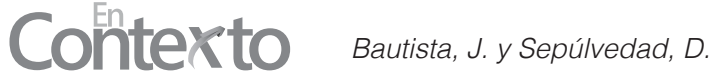

- Que exista un vendedor con claros derechos de propiedad sobre el activo, que usual o mayoritariamente es el Estado.

- Que exista un claro comprador, que está interesado en pagar un precio determinado por el activo de la empresa en referencia.

- Que en el intercambio quede claro que la intención es una transferencia de la propiedad, una transferencia del capital de unas manos a otras.

Sin embargo, Vickers y Yarrow (1996) señalan que lejos de limitar la privatización a un simple intercambio de derechos de propiedad, es un proceso muchísimo más complejo y diverso, que implica la "transferencia de las rentas obtenidas por la explotación de cualquier activo público a manos privadas, junto con cualesquiera cambios en la regulación que de allí se deriven" (Vickers y Yarrow, 1996, p.43). Por tanto, al ser la transferencia de la renta y no necesariamente de la propiedad del capital, permite hacer referencia a una serie amplia de actividades que el Estado ha desarrollado en años recientes: concesiones, alianzas estratégicas, reformas en su estructura administrativa, etc., pues son acciones que tienen como eje fundamental transferir la renta obtenida por la explotación del activo público a los privados a cambio de algún otro interés, que en este caso aparece como un interés social o público.

\section{La privatización: más allá de la venta de activos}

La definición de Vickers y Yarrow introduce complejos problemas para la comprensión de los procesos de privatización. El primero de ellos es que abre la perspectiva de las privatizaciones a una serie amplia de relaciones entre el Estado y los agentes privados, por lo que la acción privatizadora resulta ser algo más que la venta de un activo público o estatal, puede implicar la entrega total de la propiedad, o parcial cuando se habla de sociedades estratégicas, pero también puede incluirse la concesión, que otorga un privilegio especial sobre la explotación de un activo estatal a un privado, o una alianza estratégica de un operador público con uno privado a cambio de transformaciones regulatorias o administrativas que garanticen un retorno de la inversión del agente privado.

César Giraldo señala que al privatizar un activo del Estado y pasar al control privado $^{2}$, no implica la pérdida del carácter público del activo, puesto que dicho carácter no reposa en la propiedad patrimonial sino en su función económica y social (Giraldo, 2009, p.158).

El argumento de Giraldo es mucho más rico, recomendamos al lector revisar el debate sobre lo público entre César Giraldo y Salomón Kalmanovitz publicado en el periódico Un Análisis en agosto y septiembre de 2005. 
Al superar la definición patrimonialista de la privatización se abre el telón para una serie de análisis interesantes: el primero de ellos es la diferencia entre la exoprivatización, que tiene que ver con la definición señalada anteriormente por Vickers y Yarrow (1996), y la endoprivatización, que hace referencia a los cambios en la arquitectura organizacional, cuyo objetivo principal es convertir una empresa o una organización pública en generadora de rentas y utilidades, bien sea por la vía de una reducción de los costos y gastos de operación o bien mediante un incremento de los ingresos. Dicho incremento de los ingresos tiene varios factores para determinar, pues puede ocurrir por un aumento en los precios de los bienes y servicios que ofrece o por un aumento de las cantidades ofertadas en el mercado, en el primer caso estamos hablando de la posición dominante en el mercado y en el segundo, de aumentos netos de la eficiencia organizacional. La Tabla 1 muestra conceptualmente los espacios de la privatización.

Tabla 1.

Diferentes formas de privatización

\begin{tabular}{|c|c|}
\hline \multirow{5}{*}{ Endoprivatización } & Cambios en los objetivos empresariales \\
\hline & Achatamiento organizacional \\
\hline & Cambio en los incentivos internos \\
\hline & Gestión por resultados \\
\hline & $\begin{array}{l}\text { Evaluación en términos de rentabilidad } \\
\text { financiera }\end{array}$ \\
\hline \multirow{5}{*}{ Exoprivatización } & Venta de activos \\
\hline & Cesión \\
\hline & Concesión \\
\hline & Asociación - Alianza estratégica \\
\hline & Democratización accionaria \\
\hline
\end{tabular}

Elaboración propia, 2019.

El trasfondo es que la obtención de rentas o utilidades permita reducir la presión sobre el déficit fiscal propio de gobiernos que tienen tendencias inerciales al gasto público, pero pocos incentivos al cobro de impuestos (Wiesner, 2004, p. 29). Estos incentivos, entendidos como la promesa de una compensación por realizar cierta acción quien desea quien ofrece el incentivo (Laffont \& Martimort, 1997, citado por Gorbaneff, Torres, y Cardona, 2009, p.79) pueden existir aunque no haya cambiado la titularidad de la propiedad de la empresa, es 


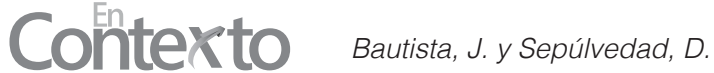

decir, sin que se haya verificado una operación clásica de privatización. Como ejemplos tenemos los procesos de reingeniería de las organizaciones públicas y el achatamiento de sus estructuras organizacionales, eventos que se ubican en lo que se conoce como el New Public Management, que consiste en la gestión de organizaciones públicas con un enfoque que se corresponde con la naturaleza de los incentivos privados (Guerrero, 2004, p.23), es decir, con la medición del desempeño organizacional con el único indicador de la ganancia privada.

\section{Proceso de privatización de Telecom: periodo 1990-2002}

En Colombia, los cambios en el sector de las telecomunicaciones comenzaron en 1989, cuando se expidió la Ley 72, la cual le dio facultades al presidente de la República para modificar la prestación del servicio de telecomunicaciones, desmonopolizarlo e iniciar la apertura hacia la competencia. Esta ley de facultades extraordinarias fue la base para la expedición de regulaciones que permitieron la liberalización del mercado. Pero en Colombia, si bien hubo alguna apertura desde el punto de vista regulatorio, no hubo un proceso de privatización paralelo, lo cual llevó a una situación de desequilibrio que habría de generar un impacto nocivo en Telecom.

\section{La primera puerta: los servicios de valor agregado}

El primer cambio de regulación se dio con el Decreto Legislativo 1900 de 1990 cuyo propósito era reformar los estatutos que regulaban el servicio de telecomunicaciones. Este decreto indicó que el servicio de telecomunicaciones podía ser prestado por operadores privados, como lo manifiesta el Artículo 2, y define el término operador: "Se entiende por operador una persona natural o jurídica, pública o privada, que es responsable de la gestión de un servicio de telecomunicaciones en virtud de autorización o concesión, o por ministerio de la Ley" (Presidencia de la República, 1990).

Pero más allá de lo anterior, el decreto explica cómo pueden ingresar al mercado operadores privados, al introducir en el Artículo 31 el concepto de servicio de valor agregado:

Servicios de valor agregado son aquellos que utilizan como soporte servicios básicos, telemáticos, de difusión, o cualquier combinación de éstos, y con ellos proporcionan la capacidad completa para el envío o intercambio de información, agregando otras facilidades al servicio soporte o satisfaciendo nuevas necesidades específicas de telecomunicaciones. 
La posterior expedición del Decreto 1794 de 1991 permitió el ingreso inmediato de personas distintas del Estado en la industria para competir con los operadores de servicios básicos. El primer servicio que se prestó fue el de transmisión de datos. Le siguieron transmisión de vos, encriptación, data-centers, fibra oscura y óptica, venta de equipos, internet y, más reciente, telefonía móvil.

Todo esto llevó a que por primera vez la telefonía pública básica conmutada local (aquella que prestaba Telecom) comenzara a afectarse por el servicio de datos terrestre y satelital, ofrecido por otras empresas que comenzaron a ocupar renglones importantes en la industria. Telecom no tenía los recursos ni el contexto administrativo y jurídico para estar a la par en la transmisión de datos con los servicios de valor agregado.

A diciembre de 1999 el Ministerio de Comunicaciones había expedido aproximadamente 220 licencias para operar servicios de valor agregado en el país, el número de operadores activos es algo menos de la mitad, entre las cuales se encuentran pequeñas empresas prestadoras del servicio de internet conmutado a nivel domiciliario, aproximadamente setenta; operadores de telefonía local, dieciséis; operadores celulares, cinco y un puñado de empresas medianas y grandes dedicadas especialmente a la prestación de la amplia gama de servicios posibles dentro del concepto de valor agregado (Presidencia de la República, 1991).

Si bien el concepto de servicio de valor agregado acabó con el monopolio de Telecom en cuanto a transmisión de datos se refiere, la empresa seguía teniendo el monopolio en el servicio de transmisión de voz y el de larga distancia nacional e internacional. Pero cuando se planteó el concepto de Grupo Cerrado de Usuarios la situación cambió sustancialmente (Figura 1); sin embargo, fue desdibujándose a medida que varias empresas adquirían la tecnología para prestar el servicio y lo comenzaron a ofrecer de manera ilegal a terceras personas. 


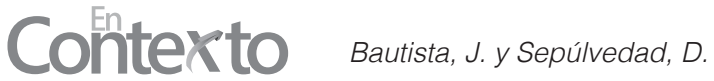

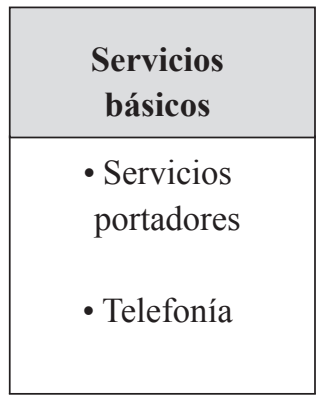

\begin{tabular}{|c|}
\hline $\begin{array}{c}\text { Servicios de } \\
\text { valor agregado }\end{array}$ \\
\hline - Transferencia \\
electrónica de \\
fondos \\
• Videotexto \\
- Teletexto \\
• Correo \\
electrónico \\
- Acceso, envío \\
y recuperación \\
de información \\
almacenada \\
\hline
\end{tabular}

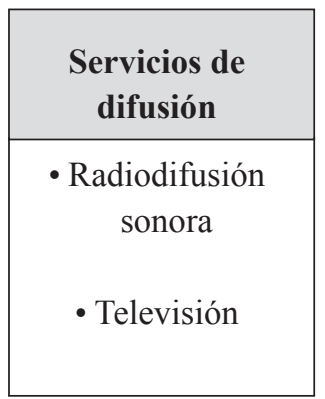

\begin{tabular}{|c|}
\hline $\begin{array}{c}\text { Servicios } \\
\text { auxiliares de } \\
\text { ayuda }\end{array}$ \\
\hline • Servicio \\
Radioeléctrico \\
de socorro y \\
seguridad \\
- Ayuda a la \\
metodología \\
- Ayuda a la \\
navegación \\
aérea o \\
marítima \\
\end{tabular}
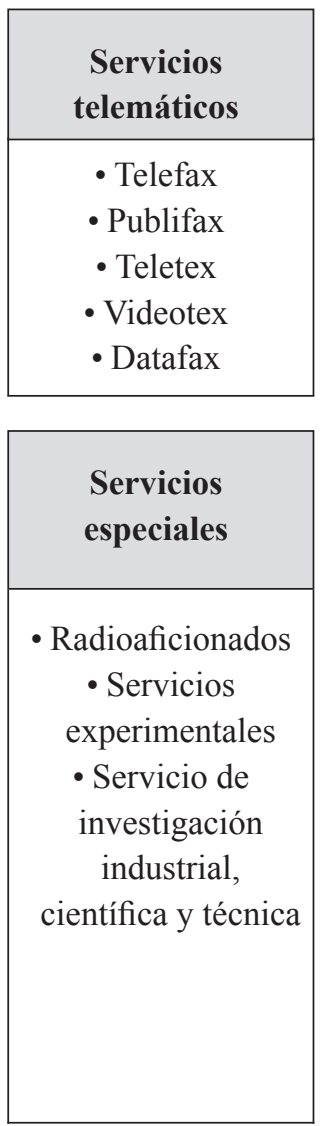

Figura 1. Servicios de valor agregado.

Elaboración propia, 2019.

\section{El desmonte de un monopolio natural}

A simple vista, la solución a las anteriores dificultades era cambiar la normatividad para permitir la libre competencia, pero esto de inmediato ponía en tela de juicio el concepto según el cual los servicios de telecomunicaciones eran un monopolio natural del Estado. De hecho, la mayoría de los expertos y entendidos del tema propugnaban este modelo, porque se consideraba que sólo el Estado estaba en capacidad de superar las barreras de entrada que requería una industria como la de las telecomunicaciones debido a los grandes niveles de inversión para tender redes y comenzar la prestación del servicio. De igual manera, las grandes economías de escala propias del Estado permitían ofrecer un servicio a un menor costo y de manera universal. Y si bien estos argumentos eran válidos, también era cierto que el "monopolio natural" del 
Estado era en gran parte promovido por una legislación que sustentaba un modelo monopolístico.

Antes de darse esta discusión, la prohibición de los monopolios del Estado quedó plasmada en la Constitución Política (C. P.) de Colombia de 1991, en el Artículo 336:

Ningún monopolio podrá establecerse sino como arbitrio rentístico, con una finalidad de interés público o social y en virtud de la ley (...) El gobierno enajenará o liquidará las empresas monopolísticas del Estado y otorgará a terceros el desarrollo de su actividad cuando no cumplan los requisitos de eficiencia en los términos que determine la ley.

El Artículo 365 de la C. P. fue más enfático al referirse directamente a los servicios públicos, liberalizando su manejo: “(...) Los servicios públicos estarán sometidos al régimen político que fije la ley, podrán ser prestados por el Estado, directa o indirectamente, por comunidades organizadas o por particulares".

El desarrollo normativo que se dio a partir de la Constitución Política de 1991, en relación con el marco regulatorio para el sector de las telecomunicaciones, se determinó bajo la premisa de desmantelar a Telecom como monopolio natural del Estado, con base en el argumento que la empresa no estaba en capacidad de suplir sola la demanda de los usuarios a un precio razonable. De esta manera se cuestionó el postulado según el cual la única manera de garantizar la universalidad del servicio era por medio de una empresa estatal que lo prestara.

\section{De establecimiento público a empresa industrial y comercial del Estado}

Mediante la Ley 72 de 1989 el Estado colombiano inició el proceso de liberalización del sector de telecomunicaciones. Esta ley se hizo realidad por medio de los Decretos 1900 de 1990 y 1794 de 1991, los cuales autorizaban la entrada de particulares a través de concesiones, amparados bajo la figura de los servicios de valor agregado. Debido a ello, el panorama de la industria y de Telecom a finales de los años 90's era muy distinto al de principios de la década.

El gobierno de César Gaviria, amparado en la Constitución de 1991, tomó el segundo paso hacia un modelo de apertura al expedir el Decreto 2123 de 1992, "Por medio del cual se reestructuró la naturaleza de Telecom", y de establecimiento público se transformó en una empresa industrial y comercial del Estado. El nuevo régimen jurídico también cambió la naturaleza de los trabajadores de Telecom, quienes pasaron de ser empleados públicos a 


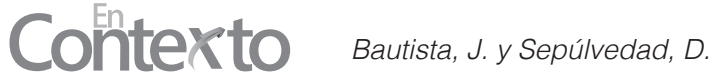

trabajadores oficiales. La nueva denominación obligaba a la empresa a una reestructuración inmediata de manera que su administración, operatividad y presupuesto se rigieran por estándares que permitieran su supervivencia en un entorno de competencia.

\section{Los joint ventures: una salvación a corto plazo}

Si bien la Ley 37 de 1993 introdujo un nuevo servicio que habría de quitarle gran participación del mercado de telecomunicaciones en el futuro a Telecom, por otro lado, apareció como un salvavidas para la empresa justo en su momento de mayor iliquidez. La ley estableció el concepto de joint ventures o contratos de asociación a riesgo compartido, los cuales permitían la asociación de empresas estatales con terceros para futuras inversiones.

Los convenios a riesgo compartido tenían vigencia de diez años, con la posibilidad de prórroga de diez más y se convirtieron en el mecanismo idóneo de financiación para la empresa. Telecom podría ampliar su red por todo el territorio nacional, evitando más pérdida de mercado. La meta era aumentar los niveles de teledensidad del país, que no superaban el 7\%, para alcanzar los índices de otros países latinoamericanos que llegaban a densidades del 13\% y el 17\%. De hecho, en el Artículo 13 de la Ley 37 de 1993 se determina que "Los contratos a riesgo compartido se establecerán también en sectores rurales y municipios de baja densidad telefónica para la ampliación de la infraestructura en telefonía pública conmutada básica local, y/o telefonía móvil celular" (Congreso de la República, 1993; Presidencia de la República, 1991).

De igual manera, los contratos a riesgo compartido permitieron cumplir los lineamientos del plan de telefonía social plasmado en el documento Conpes 2760 de 1995, titulado "Plan de desarrollo para el Sector de las telecomunicaciones". En este documento se estipula que la empresa estatal debía proveer, operar y mantener el servicio de telefonía para usuarios urbanos y rurales que, por su nivel de ingresos, no pudieran cubrir la totalidad de tarifas. Sin embargo, esta directriz de política era contradictoria, ya que pretendía llevar la telefonía a los lugares más recónditos y menos rentables del país utilizando como vehículo a empresas extranjeras cuyo cometido era asumir riesgos sólo en la medida en que estos permitieran una alta rentabilidad. Al respecto, los juristas Gustavo Suárez Camacho y Santiago Jaramillo Caro realizaron el siguiente cuestionamiento:

Este es un factor que adquiere especial peso cuando se pretende invitar al inversionista privado en el negocio, pues él no está interesado en asumir este loable riesgo si no se le garantizan unas condiciones mínimas para el retorno de su inversión (Suárez y Jaramillo, 2002, p.52). 
No obstante, durante la década de 1990, Telecom celebró un total de 19 joint ventures con la intención de instalar un millón y medio de líneas fijas por todo el país. Los primeros tres contratos, denominados "primera generación de contratos", tenían el propósito de tender más de medio millón de líneas en 15 departamentos del país. La segunda generación de contratos fue acordada a partir de 1995, incluía otros 16 departamentos y le permitió a Telecom entrar en el mercado de la telefonía local en Bogotá. A partir de 1996 se realizó la "tercera generación de contratos", con el fin de llegar a áreas rurales e ingresar en los mercados de tres ciudades: Cali, Bucaramanga y Manizales.

Los contratos funcionaban de la siguiente manera: a la empresa extranjera le correspondía poner la totalidad de la inversión para el desarrollo de la infraestructura. El número de líneas por instalar se basaba en proyecciones realizadas por el asociado, el cual inicialmente debía asumir la labor comercial de la venta de las líneas instaladas. Por su parte, Telecom se encargaba de la operación, el recaudo y el mantenimiento de la red. Durante la ejecución del contrato el asociado recibía el $100 \%$ de los cargos de conexión y entre el 50\% y el 10\% de los cargos por servicios, mientras que Telecom recibía en promedio el $15 \%$ de los cargos por servicios. Al finalizar la ejecución del contrato, la propiedad de la infraestructura nueva revertiría a Telecom y se evaluaría el flujo real de la demanda (líneas vendidas). Si el flujo era superior a las proyecciones, las empresas asociadas debían compensar a la empresa estatal. Si, por el contrario, eran inferiores, Telecom debía compensar a las asociadas.

Tabla 2.

Joint ventures: proyecciones vs. ventas

\begin{tabular}{lcccccc}
\hline \multicolumn{1}{c}{ Socio } & N. ${ }^{\circ}$ Contrato & Estimadas & Contratadas & Instaladas & Vendidas & En servicio \\
\hline Alcatel - Telfin & C-024-93 & 29.296 & 29.296 & 29.296 & 21.201 & 21.201 \\
\hline Alcatel - Sesa & C-027-93 & 267.882 & 258.252 & 258.252 & 237.130 & 220.148 \\
\hline Nortel & C-025-93 & 308.046 & 308.046 & 308.046 & 271.095 & 225.152 \\
\hline Siemens-Certel S.A. & C-017-94 & 86.350 & 86.350 & 84.644 & 83.371 & 81.209 \\
\hline Siemens & C-017-94A & 18.700 & 18.700 & 18.700 & 20.405 & 15.690 \\
\hline Ericcson - Capitel & C-061-95 & 110.000 & 110.000 & 102.280 & 59.940 & 59.940 \\
\hline NEC - Teconsorcio & C-060-95 & 110.000 & 110.000 & 96.594 & 76.420 & 69.038 \\
\hline Nortel & C-058-95 & 110.000 & 85.000 & 62.380 & 33.341 & 27.996 \\
\hline Nortel & C-058-95 & 110.000 & 110.000 & 100.725 & 84.007 & 82.053 \\
\hline Siemens & C-062-95 & 110.000 & 77.272 & 72.272 & 48.882 & 47.446 \\
\hline $\begin{array}{l}\text { Alcatael - } \\
\text { Telebachué }\end{array}$ & C-019-96 & 65.800 & 49.031 & 41.856 & 41.758 & 38.140 \\
\hline
\end{tabular}




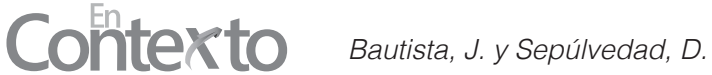

\begin{tabular}{lcccccc}
\hline \multicolumn{1}{c}{ Socio } & N. ${ }^{\circ}$ Contrato & Estimadas & Contratadas & Instaladas & Vendidas & En servicio \\
\hline $\begin{array}{l}\text { Itochu - } \\
\text { Colombiatel }\end{array}$ & C-016-96 & 31.540 & 27.070 & 25.922 & 24.977 & 22.812 \\
\hline NEC - Teconsorcio & C-018-96 & 97.400 & 94.800 & 94.800 & 80.681 & 80.681 \\
\hline $\begin{array}{l}\text { NEC - } \\
\text { Teconsorcio AD - 1 }\end{array}$ & C-018-96 & 36.093 & 39.000 & 39.700 & 31.261 & 31.261 \\
\hline $\begin{array}{l}\text { NEC - Teconsorcio } \\
\text { AD - 2 }\end{array}$ & C-018-96 & 75.371 & 77.700 & 88.700 & 57.532 & 57.532 \\
\hline Nortel & C-020-96 & 36.700 & 36.700 & 35.868 & 33.442 & 32.214 \\
\hline Ericcson - Pereira & C-014-97 & 75.000 & 75.000 & 0 & 0 & 0 \\
\hline Nec & C-015-97 & 75.000 & 51.500 & 50.500 & 25.026 & 25.026 \\
\hline Nortel & C-018-97 & 200.000 & 71.736 & 71.736 & 38.716 & 38.716 \\
\hline $\begin{array}{l}\text { Siemens } \\
\text { (Manizales) }\end{array}$ & C-016-97 & 50.000 & 28.012 & 8.176 & 7.404 & 5.132 \\
\hline $\begin{array}{l}\text { Siemens } \\
\text { (Medellín) }\end{array}$ & C-016-97 & 100.000 & 60.304 & 0 & 0 & 0 \\
\hline \multicolumn{1}{c}{ Totales } & & 2.103 .178 & 1.803 .769 & 1.590 .447 & 1.276 .589 & 1.181 .387 \\
\hline
\end{tabular}

3145 de 2001. Lineamientos de Políticas de Telecom.

Según los datos de la Tabla 3, es evidente que el número de líneas instaladas y vendidas no correspondió a la proyección inicial de los contratos y solo se vendieron 1.276 .589 líneas, es decir, el 60\% de las proyectadas. Esto pudo deberse a varios factores. Por un lado, la crisis económica a finales de la década de 1990 convirtió la telefonía en un servicio público de menor importancia, lo cual a su vez se reflejó en un menor número de líneas vendidas y en un bajo recaudo.

Por otro lado, la fortaleza de las asociadas radicaba en su capacidad tecnológica, mas no en su capacidad comercial, y si bien la labor comercial luego fue compartida con Telecom, esta última tampoco tenía la infraestructura adecuada para vender las líneas tendidas, y como el flujo real fue inferior al flujo proyectado, Telecom se vio en la obligación de compensar a sus asociados: aumentó tanto los plazos de los contratos como las participaciones de los asociados en los ingresos y realizó pagos por liquidación de convenios. A finales del 2000, las asociadas habían recibido US\$1.143 millones entre facturación, más anticipos y pagos con cargo a la liquidación final (de los contratos), lo cual representaba el $72 \%$ del ingreso proyectado de las asociadas. 


\section{La Ley 142 de 1994: servicios públicos}

Todas las normas antes mencionadas ofrecían marcos de acción para la prestación de diversos servicios de telecomunicaciones por parte de operadores privados. El desarrollo verdadero del mandato constitucional referente a la finalización de los monopolios naturales en este sentido fue la expedición de la Ley 142 de 1994, mediante la cual se estableció el régimen de los servicios públicos domiciliarios. Esta ley introdujo un nuevo régimen de servicios públicos domiciliarios en el país. Como primera medida, la ley indicaba que estos servicios podrían ser prestados por terceras personas siempre y cuando constituyeran una empresa de servicios públicos (ESP) y adquirieran una licencia del ministerio correspondiente para tales fines. En el caso de las telecomunicaciones, la ley se refería a telefonía (fija) pública básica conmutada y telefonía local móvil en el sector rural, para lo cual el prestador debía adquirir una licencia a fin de poder utilizar los espectros radioeléctricos del Estado.

Uno de los aspectos más importantes de la Ley 142 fue la creación de las comisiones de regulación como entes independientes del Ministerio de Comunicaciones. Estas nuevas entidades serían las encargadas de definir las reglas de juego en los diversos sectores. En el caso de las telecomunicaciones, a la Comisión de Regulación de Telecomunicaciones (CRT) no sólo le correspondía reglamentar la prestación de los servicios de telefonía básica conmutada y extendida, sino también conceder las licencias para la larga distancia nacional e internacional y establecer sus valores. La CRT debía, además, vigilar el sector, reglamentar el uso de las redes del Estado y fijar los cargos por interconexión. Las tarifas también serían reguladas por la Comisión y debían ser a "costo más utilidad razonable". Para ello las empresas prestadoras de servicios debían, en adelante, presentar informes contables al organismo regulador.

Otro de los cambios que introdujo la Ley 142 de 1994 fue la prohibición de los subsidios cruzados, los cuales le permitían a Telecom sostener las operaciones de empresas en áreas rurales que arrojaban pérdidas, con operaciones rentables de mercados mayores. Esto obligó a separar la contabilidad de las empresas y varias empresas de Telecom se escindieron. Más allá de lo anterior, al definir que para la prestación del servicio de telefonía local de voz no se requería una concesión, la Ley 142 abrió el camino para la libre competencia en todos los servicios de telecomunicaciones que anteriormente eran monopolio de la empresa estatal y despejó el camino para que empresas municipales pudieran prestar el servicio abiertamente. De igual manera, sentó las bases para la apertura de la larga distancia nacional e internacional. 


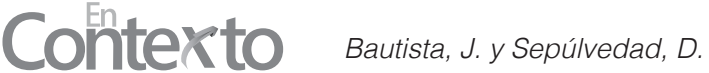

\section{Periodo 2003-2006}

El proceso de liquidación de Telecom se inició dentro de los Programas de Renovación de la Administración Pública, previo el examen de la viabilidad global de la Empresa Nacional de Telecomunicaciones, en el cual el Departamento Nacional de Planeación (DNP), a través del Conpes N. ${ }^{\circ} 3145$ de diciembre de 2001 y el Conpes 3184 de julio de 2002, concluyó que Telecom no era viable ni solvente, y que a pesar de los esfuerzos gubernamentales no se había generado mejoría en su situación financiera, como lo afirmara Javier Lastra, gerente liquidador (Presidencia de la República de Colombia, 2018).

La supresión y liquidación de Telecom se fundamentó en el Artículo 189 de la Constitución Política, numeral 15, que dispone que el Presidente de la Republica, como suprema autoridad administrativa, tiene la facultad de suprimir o fusionar entidades u organismos administrativos nacionales. Igualmente, el Artículo 52 de la Ley 489 de 1998 estableció la supresión o la transferencia de funciones de una entidad a otra cuando la evaluación de la gestión administrativa aconsejara la supresión.

Mediante los Decretos 1603 a 1615 de 2003 y el Decreto 1773 de 2004, se decidió liquidar a Telecom y 13 de sus teleasociadas, como consecuencia del proceso de transformación profunda iniciado en el sector de las telecomunicaciones, enmarcado dentro de los lineamientos que se establecieron en el documento elaborado de forma conjunta por el DNP y el Ministerio de Comunicaciones. El Decreto 1615 de 2003 ordenó la supresión y liquidación de Telecom en un plazo de dos años, prorrogables por otros dos; prohibió a la empresa iniciar nuevas actividades, garantizando la continuidad en la prestación del servicio, definió la destinación de los bienes y derechos de la Empresa, autorizó los órganos de dirección y control para la liquidación y contempló las disposiciones laborales y pensionales del proceso liquidatario. También ordenó el inventario de activos y pasivos y el avalúo de bienes.

Como parte de la estrategia diseñada por el Gobierno nacional para la liquidación de Telecom, la administración de la liquidación quedó bajo la representación de la Fiducia La Previsora S.A. Asimismo, para garantizar la continuidad en la prestación del servicio, el Decreto previó la creación de un gestor del servicio, Colombia Telecomunicaciones S. A. ESP.

La creación de Colombia Telecomunicaciones S. A. ESP, (Decreto 1616 de 2003), implicó la celebración de un contrato de explotación de bienes y activos 
entre la nueva empresa y Telecom y sus 12 Teleasociadas ${ }^{3}$ en liquidación, el 13 de agosto de 2003, con el objeto de garantizar la continuidad en la prestación de los servicios de telecomunicación ${ }^{4}$ y de generar recursos para el pago de las obligaciones en cabeza de las liquidadas.

\section{Evaluación de privatizaciones: propuesta metodológica para medir el impacto social}

La evaluación de privatizaciones es un tema sumamente complejo, en primer lugar, porque la definición sobre qué es y no es privatización impone una serie de limitantes sobre los instrumentos por aplicar, y sobre el tiempo en que deben aplicarse dichas evaluaciones. Por ende, identificar el momento en que se va a determinar el punto de quiebre para fijar el antes y el después de la privatización es un elemento fundamental en el proceso de evaluación, porque la comparación de los indicadores utilizados permite establecer las ganancias y/o pérdidas de la privatización en cada uno de los lineamientos definidos, como resultado del proceso (ver Tabla 3).

Tabla 3.

Definición del Momento de la Privatización

\begin{tabular}{|c|c|c|}
\hline Definición & Modelo amplio & Modelo tradicional \\
\hline $\begin{array}{l}\text { Momento de la } \\
\text { privatización }\end{array}$ & $\begin{array}{l}\text { La privatización ocurre cuando se } \\
\text { da el cambio en los lineamientos y } \\
\text { objetivos empresariales, o cuando } \\
\text { ocurren cambios en la regulación } \\
\text { sectorial que ponen a la empresa en } \\
\text { un contexto competitivo. }\end{array}$ & $\begin{array}{l}\text { La privatización ocurre } \\
\text { cuando se produce la } \\
\text { enajenación total o parcial } \\
\text { de un activo público. }\end{array}$ \\
\hline Marco Teórico & $\begin{array}{l}\text { Se corresponde con la definición } \\
\text { amplia de privatización } \\
\text { (Vickers y Yarrow, 1996). }\end{array}$ & $\begin{array}{l}\text { Corresponde a una } \\
\text { definición tradicional } \\
\text { de privatización. }\end{array}$ \\
\hline $\begin{array}{l}\text { Indicadores de } \\
\text { Suceso }\end{array}$ & $\begin{array}{l}\text { Reestructuraciones, } \\
\text { “modernización” en la gestión, } \\
\text { cambios en la misión, visión, } \\
\text { objetivos, nueva arquitectura. }\end{array}$ & $\begin{array}{c}\text { Proceso de venta o } \\
\text { enajenación del capital } \\
\text { accionario. }\end{array}$ \\
\hline
\end{tabular}

Elaboración propia, 2019.

\footnotetext{
${ }^{3}$ Las 12 Teleasociadas fueron: Cartagena, Caquetá. Valledupar, Maicao, Huila, Nariño, Armenia, Calarcá, Santa Rosa de Cabal, Tolima, Buenaventura y Tuluá.

4 Tales como (...)telefonía básica local y de larga distancia, servicios móviles, portadores, teleservicios, telemáticos, de valor agregado, servicios satelitales, servicios de internet y cualquier otro servicio calificado como de telecomunicaciones, comunicaciones e información(...) dentro del territorio nacional y en el exterior" (Presidencia de la República, Decreto 1616/2003, Art. 4).
} 


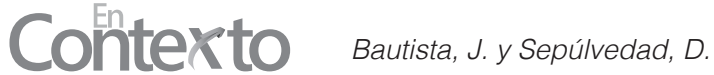

La discusión sobre lo que se considera privatización no ha tenido la mayor importancia en Colombia. Pero es claro que privatizar no solamente implica una venta de un activo estatal, sino también un conjunto de medidas políticas tendientes a lograr que las instituciones gubernamentales se comporten bajo incentivos de mercado.

En segundo lugar, las herramientas de evaluación son muy poco conocidas y aplicadas en nuestro contexto, y cuando ello ocurre es más por un ejercicio de curiosidad académica que por una necesidad política. Aunque en realidad muchas herramientas están contenidas en mandamientos legales, y muy particularmente en la Ley 42 de 1993. Es curioso ver cómo en la ley de privatizaciones no hay referencia alguna a la evaluación de los procesos de privatización.

La fuente primaria de los análisis de privatizaciones proviene de la escuela anglosajona. Para autores como Yarrow y Vickers (1996), , las privatizaciones son un medio para mejorar la eficiencia y la eficacia en la provisión de servicios públicos, pero dicho mejoramiento tiene relación directa con la competencia (real o inducida) de los mercados, con las estructuras de incentivos y, claro está, con la composición de las fuerzas políticas que concurren en dichos procesos, lo cual incluye las estructuras laborales de las organizaciones públicas.

De ello se desprende la necesidad de evaluar la eficiencia y la eficacia organizacionales antes y después de la privatización. Si de dicha evaluación se concluye que la privatización incrementó la eficiencia y la eficacia organizacionales, que deben traducirse en elementos como más y mejores servicios, tarifas más bajas, etc., se debe concluir que la privatización ha sido afortunada, en caso contrario, que la privatización no ha sido adecuada a dicho mercado u organización, y en este caso el activo debe regresar a la gestión y propiedad del Estado, o se deben buscar mecanismos regulatorios mucho más estrictos que garanticen la máxima eficiencia organizacional posible.

Esto quiere decir que las privatizaciones se asumían dentro de un enfoque pragmático cuyo objetivo final era mejorar las condiciones de operación de los activos que estaban en manos del Estado, lo que contrasta con los enfoques dogmáticos que hicieron (y siguen haciendo) carrera en América Latina, en los cuales las privatizaciones por sí solas garantizan mayor eficiencia organizacional sin que ello demande ningún tipo de discusión adicional. En este contexto, la preocupación es sobre las formas más eficaces de privatizar y los mecanismos más adecuados para 'maximizar' el valor financiero de los activos sometidos a privatización. 
Por ello, en contextos como el colombiano la evaluación de privatizaciones dista mucho de ser una acción institucionalizada, lo que sumado a un contexto político en el que no existe ningún interés por conocer las consecuencias de dicha privatización, genera un desconocimiento casi total en la materia.

\section{¿Cómo evaluar las privatizaciones?}

La evaluación de la gestión o medición del desempeño es una de las grandes transformaciones implícitas en el proceso de reformas de la administración pública en el mundo. Los desarrollos en las teorías organizacionales alrededor de los principios de agencia, de visibilización y transparencia de la gestión de las organizaciones públicas (Accountability), y la discusión de los criterios sobre los cuales deben ser evaluadas dichas organizaciones, son elementos que han sido incorporados en la gestión organizacional del Estado en Colombia.

Los estudios sobre privatizaciones en Colombia han pasado por alto la necesidad de hacer evaluaciones sobre el impacto micro y macro de dichos procesos. En la teoría, la ley de control fiscal ordena el establecimiento de una amplia serie de variables que se deben tener en cuenta para la evaluación de la gestión fiscal de las empresas públicas. En este sentido, la Ley 42, en su Artículo 8, señala las dimensiones para la evaluación de la gestión fiscal (Figura 2), las cuales sirven como guía para medir el desempeño de las unidades institucionales pertenecientes al sector público, y muy especialmente de sus unidades empresariales.

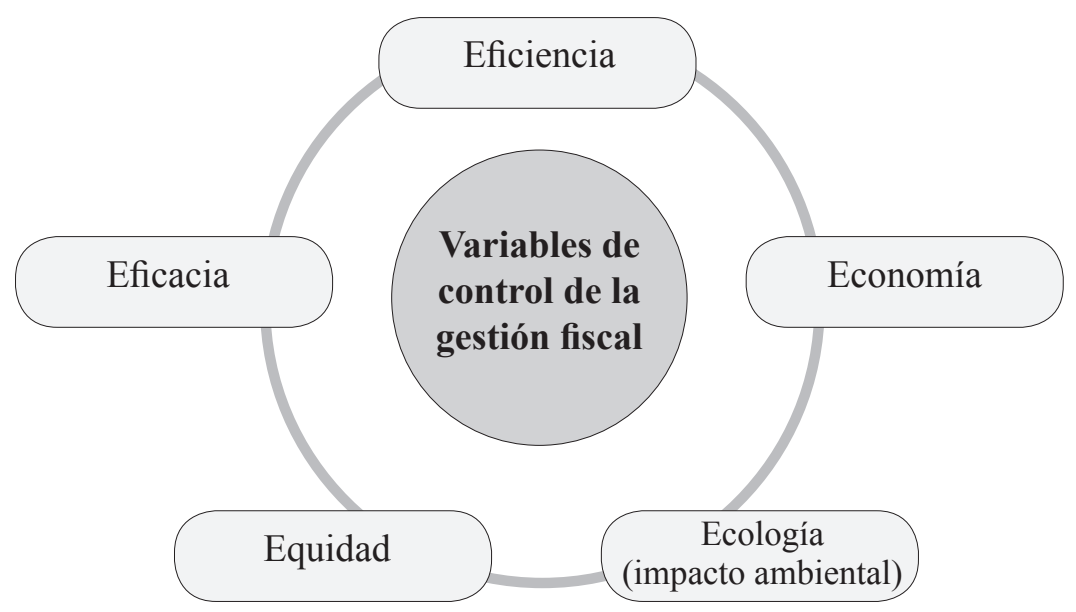

Figura 2. Metodología para evaluación de la gestión fiscal.

Elaboración propia, 2019. 


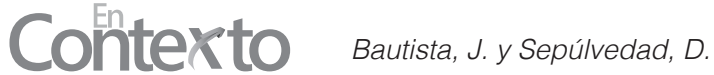

Como cada uno de estos elementos guía debe poderse medir de forma concreta, se establece la necesidad de hacer evaluaciones de impacto mediante la aplicación de herramientas de medición de la gestión del activo público antes (ex-ante) y después (ex-post) de la privatización.

Pero dichas evaluaciones también deben analizar el impacto social de las privatizaciones. Aquí se entiende lo social como el conjunto de grupos de interés que confluyen en una organización, cada uno de estos grupos concurre a la firma para maximizar su bienestar en ella, pero también para mejorar su posición relativa en la distribución de la riqueza producida por la firma. Esta visión, heredada de la interpretación de la economía neoinstitucional, remite el análisis de lo social a las formas en que los diferentes grupos sociales que concurren en la firma cambian su participación en la producción y distribución de la riqueza generada.

La privatización cambia el peso relativo de dichos actores en la firma, y esto puede implicar mejoras netas globales en la eficiencia global de la organización, o implicar mejoras relativas de algunos grupos que aparecen como dominantes en ella. Por ejemplo, en una empresa plenamente privatizada el peso de los intereses de accionistas y gerentes puede ser más alto que el de los usuarios o el de los trabajadores, de tal manera que un aumento sustancial de las ganancias financieras se interpreta como una ganancia en el total de la eficiencia organizacional, pero esta puede haber sido lograda por medio de la rebaja general de salarios o como consecuencia de un aumento en las tarifas.

Por ello la evaluación de privatizaciones debe contemplar un proceso de medición integral que tenga en cuenta la globalidad de la eficiencia organizacional y la necesidad de medir los cambios relativos en la producción y distribución de la riqueza generada por la organización. La ley 42 de 1993 señala dicha integralidad en el sistema de control fiscal, cuando indica que los elementos fundamentales de la evaluación deben comprender cinco dimensiones (eficiencia, eficacia, economía, equidad e impacto medio ambiental), y bajo cada uno de ellos debe haber un sistema de indicadores que permita verificar el cumplimiento de dichos principios.

\section{Conclusiones}

En los procesos de privatización en Colombia ha reinado una visión estrictamente técnico-instrumental. El debate sobre las ventajas de la privatización de activos del Estado no ha girado sobre la eficiencia económica o el bienestar social, sino escasamente sobre las estructuras regulatorias que debe desplegar el Estado 
como resultado de los procesos, y especialmente sobre los aspectos fiscales que encierra el proceso (quién compra la empresa, bajo qué forma se vende la empresa, y el precio al cual se vende el activo). Así, quedan fuera del debate público factores como el reacomodamiento político de los agentes que confluyen en las empresas, las formas de apropiación del excedente, los sistemas de incentivos de la dirección, el impacto macroeconómico o la arquitectura regulatoria que debe garantizar el servicio de la empresa privatizada al interés público.

En este sentido, es necesario emprender procesos de investigación y análisis sobre los resultados de los procesos de privatización emprendidos en Colombia, que superen la estrecha visión del beneficio financiero y que resalten aspectos como el mejoramiento en la calidad de los servicios ofrecidos, los impactos sobre el sistema de tarifas, el bienestar social y la distribución del ingreso, o los excedentes percibidos por los agentes privados que compran los activos del Estado.

La sociedad colombiana se encuentra en un avanzado proceso de deslegitimación institucional y de creciente privatización de lo público. Las políticas públicas deben fortalecerse en la defensa del patrimonio y las finanzas públicas y en pro de la proclamación constitucional sobre un Estado social de Derecho, donde lo esencial son los derechos sociales de los colombianos, pues la política de privatización solo vislumbra el agravamiento de las condiciones actuales de desigualdad y el impacto negativo que esto tiene sobre la distribución del ingreso y el bienestar social.

Las leyes y decretos emanados a partir de la Constitución de 1991 permitieron la apertura del sector de telecomunicaciones a finales del siglo XX en Colombia. Las normas que se expidieron a finales de la década de 1990 liberalizaron el sector en su momento y acabaron con el régimen monopolístico de Telecom, que más adelante reflejó múltiples oligopolios privados. Hubo dos agravantes: 1) aunque se fomentó el desarrollo del sector telecomunicaciones, se hizo en detrimento de la gran empresa estatal, ya que no se acompañó de cambios administrativos y financieros en Telecom; 2) las discusiones se centraron en la flexibilidad de las normas, y poca fue la atención que se prestó a la flexibilidad y la verdadera capacidad de competencia de la empresa en sí, lo cual cercenó su capacidad de competir en el nuevo entorno.

La supresión y liquidación de Telecom y la creación de una nueva empresa (Coltel), como una sociedad anónima, fue la forma escogida por el Gobierno para implementar la política pública de privatización de las telecomunicaciones. Al ceder el control de la junta directiva al agente privado el Estado perdió 


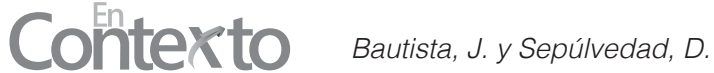

el control de la empresa de telecomunicaciones más importante de Colombia por su experiencia acumulada, cobertura, infraestructura, tecnología y por la diversificación de sus servicios.

En este contexto, surgen las siguientes preguntas: ¿Estaba Telecom en capacidad de competir en un mercado abierto? ¿Por qué los directivos de la empresa y los gobiernos de turno no tomaron las medidas necesarias para que no tuviera que ser liquidada?

\section{Referencias}

Cabeza, L. (2011). Los procesos de privatización en España: determinantes e implicaciones. Madrid: Editorial Académica Española.

Cárdenas, M. (1994, junio-agosto). El sector privado imejor que el sector público? Colombia. Economía Colombiana, (22). Contraloría General de la República.

Congreso de la República de Colombia. (1993). Ley 37 de 6 de enero de 1993. "Por la cual se regula la prestación del servicio de telefonía móvil celular, la celebración de contratos de sociedad y de asociación en el ámbito de las telecomunicaciones y se dictan otras disposiciones". Diario Oficial, 40.710. Bogotá, Colombia.

Congreso de la República de Colombia. (1989). Ley 72 de 1989. "Por la cual se definen nuevos conceptos y principios sobre la organización de las telecomunicaciones en Colombia y sobre el régimen de concesión de los servicios y se confieren unas facultades extraordinarias al Presidente de la República". Bogotá.

Congreso de la República de Colombia. (1994). Ley 142 de 11 de julio de 1994. "Por la cual se establece el régimen de los servicios públicos domiciliarios y se dictan otras disposiciones". Diario Oficial, 41.433.

Consejo Nacional de Política Económica y Social (Conpes). (1995). Plan de desarrollo para el Sector de las telecomunicaciones. Documento Conpes N. ${ }^{\circ} 2760$. Bogotá: DNP, Mincomunicaciones.

Consejo Nacional de Política Económica y Social (Conpes). (2001, diciembre). Lineamientos de política para Telecom. Documento Conpes N. ${ }^{0} 3145$. Bogotá: DNP, Ministerio de Hacienda, Ministerio de Comunicaciones. 
Consejo Nacional de Política Económica y Social (Conpes). (2002, julio). Seguimiento a las Acciones Definidas en el Documento Conpes 3145 Lineamientos de Política para Telecom. Documento Conpes N. ${ }^{\circ} 3184$. Bogotá: DNP, Ministerio de Hacienda, Ministerio de Comunicaciones.

Giraldo, C. (2009). Finanzas públicas en América Latina: La Economía Política. Bogotá: Desde Abajo.

Gorbaneff, Y., Torres, S. y Cardona, J. (2009). El Concepto de Incentivo en Administración. Una Revisión en la Literatura. Revista de Economía Institucional, 11(21), 73-91.

Guerrero, O. (2004). El mito del nuevo "Management" público. Revista Venezolana de Gerencia (RVG), 9(25), 9-52.

Hayek, F. (2002). Camino de Servidumbre. Madrid: Alianza Editorial.

Laffont, J. \& Martimort, D. (1997). The Firm as a Multicontract Organization. Journal of Economics and Management Strategy, 2(6), 201 - 234.

Matías, S. (2001). Los servicios públicos domiciliarios en Colombia. Análisis socio-jurídico. Bogotá: Panamericana Formas e Impresos S. A.

Presidencia de la República de Colombia. (1991). Decreto 1794 de 15 de julio de 1991. "Por el cual se expiden normas sobre los Servicios de Valor Agregado y Telegráficos y se reglamenta el Decreto 1900 de 1990”. Bogotá.

Presidencia de la República de Colombia. (1992). Decreto 2123 de 29 de diciembre de 1992. "Por el cual se reestructura la Empresa Nacional de Telecomunicaciones (Telecom) y se ordena su liquidación".

Presidencia de la República de Colombia. (2005, enero). "Liquidación de Telecom, Teleasociadas, Inravisión y Audiovisuales tiene acelerador a fondo". Presidencia de Colombia. Prensa. Recuperado de http://historico. presidencia.gov.co/prensa_new/sne/2005/enero/26/19262005.htm

Presidencia de la República de Colombia. (1990). Decreto 1900 de 19 de agosto de 1990. "Por el cual se reforman las normas y estatutos que regulan las actividades y servicios de telecomunicaciones y afines". Bogotá.

Presidencia de la República de Colombia. (2003). Decreto 1615 de junio de 2003. "Por el cual se suprime la Empresa Nacional de Telecomunicaciones Telecom- y se ordena su liquidación". Diario Oficial, 45.217. 


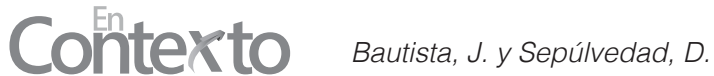

Presidencia de la República de Colombia. (2003). Decreto 1773 de 2004. "Por el cual se suprime la Empresa de Telecomunicaciones de Santa Marta, Telesantamarta S. A. ESP y se ordena su disolución y liquidación". Diario Oficial, 45.570.

Suárez, G. y Jaramillo, S. (2002). Los contratos de asociación a riesgo compartido en telecomunicaciones. Revista Derecho Público, 14, $49-78$.

Vickers, J. y Yarrow, G. (1996). Aproximaciones económicas a la privatización. Privatización, desregulación y ¿competencia? Madrid: Civita.

Wiesner, J. (2004). El origen político del déficit fiscal: el contexto institucional 20 años después. Documentos CEDE, $n .^{\circ} 20$. Universidad de los Andes. Recuperado de https://economia.uniandes.edu.co/components/com booklibrary/ebooks/d2004-20.pdf

\section{Para citar este artículo:}

Bautista, J. y Sepúlvedad, D. (2019). Evaluación de la política de privatización en las empresas estatales de Colombia. Análisis de caso Telecom 1990-2010. En-Contexto, 7(11), 63-86. 